\title{
The European Journal of General Practice
}

\section{Use of oral anticoagulants in atrial fibrillation is highly variable and only weakly associated with estimated stroke risk: Cross-sectional population database study}

\author{
Tobias Dreischulte, Karen Barnett, Vishnu Madhok \& Bruce Guthrie
}

To cite this article: Tobias Dreischulte, Karen Barnett, Vishnu Madhok \& Bruce Guthrie (2014) Use of oral anticoagulants in atrial fibrillation is highly variable and only weakly associated with estimated stroke risk: Cross-sectional population database study, The European Journal of General Practice, 20:3, 181-189, DOI: $10.3109 / 13814788.2013 .852535$

To link to this article: https://doi.org/10.3109/13814788.2013.852535

Published online: 19 Dec 2013.

Submit your article to this journal $\sqsubset$

Џlll Article views: 432

Q View related articles $\square$

View Crossmark data ¿

Citing articles: 9 View citing articles $₫$ 


\title{
Original Article
}

\section{Use of oral anticoagulants in atrial fibrillation is highly variable and only weakly associated with estimated stroke risk: Cross-sectional population database study}

\author{
Tobias Dreischulte ${ }^{1,2}$, Karen Barnett ${ }^{2}$, Vishnu Madhok ${ }^{3}$ \& Bruce Guthrie ${ }^{3}$ \\ ${ }^{1}$ Tayside Medicines Governance Unit, NHS Tayside, Dundee, UK, ${ }^{2}$ University of Edinburgh, Edinburgh, UK, and \\ ${ }^{3}$ University of Dundee, Dundee, UK
}

KEY MESSAGE:

- Use of oral anticoagulants in atrial fibrillation varies substantially between practices and is only weakly associated with stroke risk.

- Using stroke and bleeding risk stratification tools is a plausible but untested strategy to improve decision making on oral anticoagulation in atrial fibrillation, which should be evaluated in pragmatic trials.

\begin{abstract}
Background: Current international guidelines promote the use of stroke risk stratification tools to inform decision making about oral anticoagulant (OAC) use in atrial fibrillation (AF).

Objectives: To examine (a) differences between $\mathrm{CHADS}_{2}$ and $\mathrm{CHA}_{2} \mathrm{DS}_{2}$ VASc in classifying stroke risk in a primary care population of AF patients; (b) patterns of use of antithrombotics by stroke risk; and (c) patient and practice characteristics associated with use of oral anticoagulants in patients with AF.

Methods: Cross-sectional multilevel modelling study of all patients with AF and without rheumatic heart disease or valve replacement $(n=21564)$ from 315 Scottish General Practices.

Results: (a) $\mathrm{CHADS}_{2}$ characterized $30.3 \%$ in the intermediate and $53.8 \%$ in the high-risk category, compared to $\mathrm{CHA}_{2} \mathrm{DS}_{2} \mathrm{VASC}_{\text {only }}$ 9.7\% intermediate and $85.1 \%$ high-risk. (b) Of included patients, $17.8 \%$ were currently not prescribed any antithrombotic and $43.3 \%$ were on OAC. OAC use was only weakly related to stroke risk. (c) Patients with paroxysmal AF and those with dementia and previous peptic ulcer (adjusted ORs $0.26,0.25$ and 0.79 ) were less likely to be prescribed OAC. OAC use varied over five-fold between practices after adjustment for patient case mix, with remote and non-training practices and those with high levels of high-risk prescribing being more likely to prescribe OAC.
\end{abstract}

Conclusion: Evidence was found of both underuse and overuse of OAC in patients with AF. Promoting instruments for stroke risk assessment in $\mathrm{AF}$ is a plausible but untested strategy to improve decision making in $\mathrm{AF}$, and its impact on OAC prescribing and patient outcomes should be evaluated in pragmatic trials.

Keywords: atrial fibrillation, family practice, quality of health care, stroke risk, antithrombotics

\section{INTRODUCTION}

Atrial fibrillation (AF) is common, affecting approximately $1 \%$ of the general population ( 4.5 million patients in the European Union), and its prevalence is estimated to at least double in the next 50 years due to aging populations (1-3). AF is associated with a five-fold increase in the risk of stroke (4) and oral anticoagulation
(OAC) significantly reduces this risk by approximately $60 \%$ in patients of all ages (5). OAC is substantially more efficacious than aspirin in preventing stroke (by approximately $40 \%$ ) but approximately doubles the risk of intracranial haemorrhage (6). Nevertheless, all-cause mortality is significantly reduced (by approximately $25 \%)$ under OAC compared to aspirin treatment, and

Correspondence: Tobias Dreischulte, Research pharmacist, Tayside Medicines Governance Unit, NHS Tayside, Dundee, UK, c/o Population Health Sciences, Quality, Safety and Informatics Research Group, University of Dundee, Mackenzie Building, Kirsty Semple Way, Dundee DD2 4BF, UK. Tel. + 44 (0)1382 383800. Fax + 44 (0)1382 383802. E-mail: t.dreischulte@dundee.ac.uk 
despite the costs associated with international normalized ratio (INR) monitoring, OAC use has been shown to be cost-effective in AF patients with additional risk factors for stroke $(7,8)$.

Although major bleeding events are estimated to be five-to-eight times less likely than ischaemic strokes and there is a clear net benefit of OAC use in AF (especially when stroke risk is high), major bleeding events may be devastating when they do occur (9). For all patients, prescribers, therefore, have to balance the risks and benefits of OAC and aspirin, and current guidelines recommend the use of stroke risk-stratification schemes, which generally use a three-fold classification: 'High-risk' patients are generally recommended for OACs and 'low-risk' patients for aspirin or no antithrombotic treatment, while 'intermediate-risk' patients are recommended for either OAC or aspirin $(4,10,11)$. However, antithrombotic treatment in atrial fibrillation is used inconsistently, and particular concern has been raised over underuse of OAC in patients with high risk of stroke $(12,13)$.

The risk-classification scheme most commonly recommended in guidelines internationally is the $\mathrm{CHADS}_{2}$ score (Box 1) (4,14-16), which is also promoted by the current (2012/13) version of the United Kingdom (UK) Quality and Outcomes framework (QOF) (a system of financial incentives offered to general practices for their achievements against a range of quality indicators relating mainly to care for long-term conditions) (17). However, $\mathrm{CHADS}_{2}$ has been criticized not only for classifying large proportions of patients into the intermediate risk group where treatment recommendations

Box 1. Points scored for stroke risk factors under $\mathrm{CHADS}_{2}(14,43)$ and $\mathrm{CHA}_{2} \mathrm{DS}_{2}$ VASC (43). Under both schemes, the scored points are summed, with $0=$ 'low risk', $1=$ 'intermediate risk' and $\geq 2=$ 'high risk'.

\begin{tabular}{|lcc|}
\hline & \multicolumn{2}{c|}{ No. of points scored under } \\
\cline { 2 - 3 } Risk factor & CHADS $_{2}$ & CHA $_{2}$ DS $_{2}$ VASc \\
\hline Congestive heart failure & 1 & 1 \\
Hypertension & 1 & 1 \\
Aged $\geq 75$ years & 1 & 2 \\
Diabetes mellitus & 1 & 1 \\
Stroke, TIA or thromboembolic & 2 & 2 \\
$\quad$ event & Not included & 1 \\
Vascular disease (prior & & \\
$\quad$ myocardial infarction, & & \\
peripheral arterial disease & & \\
$\quad$ or complex aortic plaque & & 1 \\
$\quad$ on transthoracic & & \\
$\quad$ echocardiogram & & \\
Aged $65-74$ years & & Not included \\
Sex, female & Not included & 1 \\
\hline
\end{tabular}

${ }^{a}$ Transoesophageal echocardiogram is not a routine investigation in patients with simple AF in UK primary care, and is not routinely coded in primary care records, so not included. are ambiguous $(18,19)$, but also for misclassifying patients as intermediate risk of stroke who are in fact low-risk (potentially exposing them unnecessarily to the risks and burdens of OACs (20)) or high-risk (potentially denying them the benefits of OAC (19)).

Partly in response, a revised scheme ( $\left.\mathrm{CHA}_{2} \mathrm{DS}_{2} \mathrm{VASc}\right)$ has been developed, which includes additional risk factors for stroke (Box 1). A merit of $\mathrm{CHA}_{2} \mathrm{DS}_{2}$ VASc is that it predicts better who is low-risk, and current European guidelines, therefore, recommend its use to more clearly identify those patients with $\mathrm{CHADS}_{2}=1$, who are unlikely to benefit from OAC. $\mathrm{CHA}_{2} \mathrm{DS}_{2}$ VASc does not, however, solve the problem of misclassifying low-risk patients as intermediate risk $(4,20)$ and neither scheme is superior to the other in terms of its overall predictive ability for stroke, which is modest at best $(21,22)$.

The aims of this study were (a) to examine differences between the $\mathrm{CHADS}_{2}$, and $\mathrm{CHA}_{2} \mathrm{DS}_{2}$ VASc schemes in classifying stroke risk in a population of AF patients, (b) to investigate patterns of use of antithrombotic treatment by stroke risk, and (c) to identify patient and practice characteristics associated with use of oral anticoagulants.

\section{METHODS}

\section{Data source}

Data was extracted from the Primary Care Clinical Informatics Unit (PCCIU) at University of Aberdeen, which contains data of registered patient populations from 315 (31\%) of Scottish general practices, that are representative of Scotland as a whole in terms of age and socio-economic deprivation (23).

\section{Study population}

Patients were eligible for inclusion if they were alive on the index date (31 March 2007), permanently registered with the practice and had a Quality and Outcomes Framework (QOF) defined Read Code for atrial fibrillation or flutter (24) recorded on or before the index date. Patients with a most recently recorded code of 'AF resolved' were excluded, as were those with a history of rheumatic heart disease or valve replacement surgery (defined using QOF Read Codes where available (24), and bespoke code-sets where necessary), to focus attention on those to whom current guidelines applied.

\section{Antithrombotic prescriptions}

The most recent date of prescription of oral anticoagulation (OAC, defined as drugs in British National Formulary (BNF) section 2.8.2), and antiplatelet drugs (aspirin, clopidogrel or dipyridamole preparations in BNF section 2.9) was extracted, as was the date last recorded 
for non-prescription aspirin use (as defined by QOF) (24). Current treatment was defined as a prescription issued in the 12 weeks before the index date, or over the counter (OTC) aspirin use recorded in the previous year (since QOF incentivises at least annual recording of OTC aspirin use).

\section{Co-variables}

At patient level, age, sex, Carstairs deprivation score (25), number of active repeat drugs and the presence of stroke risk factors (i.e. coronary heart disease, heart failure, diabetes, hypertension, peripheral vascular disease, prior stroke or transient ischaemic attack as defined by QOF) and relative contraindications for the use of antithrombotics, i.e. peptic ulcer (defined by relevant Read codes) and dementia (defined by relevant Read codes or prescription of an acetylcholinesterase inhibitor), were considered (26). At practice level, list size, urban/rural location, accreditation for postgraduate training, dispensing status and contract status (General Medical Services or Personal Medical Services contract), and a composite indicator of rates of high-risk prescribing were considered (27). The latter comprised of 15 validated indicators of hazardous prescribing of drugs in clinical situations identified as clearly high risk in the British National Formulary, clinical guidelines or national safety alerts and commonly implicated in drug-related hospital admissions or in drug-related death $(27,28)$.

\section{Data analysis}

For analyses examining current treatment, those diagnosed less than 12 weeks before the index date were excluded, since decisions about antithrombotic treatment in newly diagnosed AF can be prolonged. Stroke risk on index date was calculated using the $\mathrm{CHADS}_{2}$, and $\mathrm{CHA}_{2} \mathrm{DS}_{2}$ VASc schemes. Current use and use of OAC ever since diagnosis of AF by each scheme were calculated.

Multilevel logistic regression was used to examine how current OAC treatment was associated with patient and practice characteristics, and variation between practices after accounting for differences in patient characteristics. Univariable and adjusted odds ratios were calculated for patient and practice variables. Variation between practices was examined by estimating residual variation at practice level in a model with patient variables fitted to account for differences in case-mix (29). All models were fitted with second order penalized quasi-likelihood estimation, and assumptions of normality of level 2 residuals checked graphically. Initial analysis was carried out in SPSS v17.0, and multilevel logistic regression in MLWin 2.0 (Centre for Multilevel Modelling, University of Bristol, UK).

\section{RESULTS}

\section{Study population}

There were 1760223 permanently registered patients on the index date, of whom 21096 (crude prevalence $1.20 \%$ ) were recorded as having atrial fibrillation as defined above. For the analyses relating to current treatment, 653 patients diagnosed in the 12 weeks before index date were excluded. Table 1 shows the demographics of patients without rheumatic heart disease or valve replacement. AF prevalence rose steeply with age, comorbidity was common and the median number of oral repeat drugs co-prescribed with any anticoagulant was five.

\section{Differences between risk stratification schemes}

Table 2 shows classification of stroke risk for the two schemes. $\mathrm{CHADS}_{2}$ characterizes almost a third of patients (30.3\%) in the intermediate-risk category. In contrast, and by design, $\mathrm{CHA}_{2} \mathrm{DS}_{2}$ VASC classifies only $9.7 \%$ as intermediate-risk but most patients (85.1\%) as high-risk (31.3\% more than $\mathrm{CHADS}_{2}$ ).

\section{Antithrombotic treatment by stroke risk}

A total of $17.8 \%$ patients were not prescribed any antithrombotic treatment, $38.9 \%$ were only prescribed antiplatelets, $39.1 \%$ only OAC, and $4.3 \%$ OAC plus an antiplatelet (Table 3). Overall, therefore, $43.3 \%$ of

Table 1. Demographics of 21096 patients with atrial fibrillation without rheumatic heart disease or valve replacement.

\begin{tabular}{lc} 
Basic demographics & \\
Male & $54.6 \%$ \\
Mean age in years (95\% CI) & $75.5(75.3-75.6)$ \\
Prevalence of atrial fibrillation by age & \\
$\quad$ group (95\% CI) & \\
$45-54$ years & $0.3 \%(0.2$ to 0.3$)$ \\
$55-64$ years & $1.1 \%(1.0-1.1)$ \\
$65-74$ years & $3.5 \%(3.4-3.6)$ \\
$75-84$ years & $7.8 \%(7.7-8.0)$ \\
85 years and over & $12.2 \%(11.9-12.6)$ \\
Prevalence of comorbidity in patients with & \\
$\quad$ atrial fibrillation & \\
Hypertension & \\
Coronary heart disease & $54.7 \%(54.0-55.3)$ \\
Heart failure & $38.6 \%(37.9-39.2)$ \\
Diabetes & $20.6 \%(20.0-21.1)$ \\
Non-haemorrhagic stroke or TIA & $16.5 \%(16.0-17.0)$ \\
Peripheral vascular disease & $13.5 \%(13.0-14.0)$ \\
Dementia & $6.6 \%(6.3-7.0)$ \\
Previous peptic ulcer & $4.9 \%(4.6-5.2)$ \\
No. of oral repeat drugs in addition to an oral & $10.0 \%(9.6-10.4)$ \\
$\quad$ anticoagulant & \\
Mean (95\% Cl) & \\
Median (Interquartile range) & $5.6(5.55-5.63)$ \\
\hline
\end{tabular}


Table 2. Predicted risk category for 21096 patients with atrial fibrillation without rheumatic heart disease or valve replacement.

\begin{tabular}{lccc}
\hline & $\begin{array}{c}\text { Low risk } \\
n(\%)\end{array}$ & $\begin{array}{c}\text { Intermediate risk } \\
n(\%)\end{array}$ & $\begin{array}{c}\text { High risk } \\
n(\%)\end{array}$ \\
\hline $\mathrm{CHADS}_{2}$ & $3358(15.9)$ & $6396(30.3)$ & $11342(53.8)$ \\
$\mathrm{CHA}_{2} \mathrm{DS}_{2}$ VASc & $1109(5.3)$ & $2039(9.7)$ & $17948(85.1)$ \\
\hline
\end{tabular}

patients were current OAC users, although $58.5 \%$ had used OAC at some point since diagnosis of AF. For both risk stratification schemes, fewer patients were on no treatment as risk increased, but current OAC use was similar in high and intermediate-risk groups (42-44\%) and only marginally higher than in low-risk groups ( $\mathrm{CHADS}_{2}$ 35.2\%; $\mathrm{CHA}_{2} \mathrm{DS}_{2}$ VASc 28.6\%).

\section{Patient and practice characteristics associated with current OAC treatment}

Table 4 shows how receipt of current OAC varies by patient and practice characteristics. Among the patientlevel variables investigated, age, AF type, and relative contraindications showed the strongest associations with current anticoagulant use in multivariate analyses. Patients aged 65-74 years were more likely to be currently prescribed OAC, while younger and older patients were progressively less likely to ( $34 \%$ of patients aged 85 or older versus $52.2 \%$ of $65-74$ year olds, adjusted OR: 0.33, 95\% Cl: 0.30-0.36). Patients with paroxysmal AF were much less likely to be anticoagulated than those with chronic AF ( $20.0 \%$ versus $46.7 \%$, adjusted OR: 0.26 , $95 \% \mathrm{Cl}: 0.23-0.29$ ), as were those with dementia and (to a lesser extent) those with previous peptic ulcer. Strong associations were also found between current OAC use and the number of drugs prescribed. Patients on three to five drugs were most likely to be prescribed OAC, while those on more drugs were progressively less likely to $35.7 \%$ in those on 12 or more drugs versus $49.0 \%$ in those on three to five drugs, adjusted OR: $0.55,95 \% \mathrm{Cl}$ : $0.45-0.66)$. Weaker associations were found for gender and comorbidity (Table 3 ).

Patients registered with more remote and nontraining practices were more likely to be anticoagulated in both univariable and adjusted analyses as were those in practices with the highest rates of 'highrisk prescribing' (27). At practice-level, a median of $44.4 \%$ (interquartile range: $37.8-52.0$ ) of patients were currently anticoagulated. After adjustment for patientlevel characteristics in the multilevel model, the odds of an individual receiving OAC varied from $0.39(95 \% \mathrm{Cl}$ : $0.30-0.51$ ) in the practice with lowest use to 2.13 $(95 \% \mathrm{Cl}: 1.35-3.36)$ in the practice with highest use; 20 (6.3\%) practices had significantly higher than average, and $25(7.9 \%)$ significantly lower than average OAC use (Figure 1).

\section{DISCUSSION}

\section{Main findings}

In this study, the $\mathrm{CHADS}_{2}$ classification scheme classified almost two thirds of patients into the intermediate stroke risk category. In comparison, $\mathrm{CHAD}_{2} \mathrm{VA}_{2} \mathrm{Sc}$ classifies many fewer patients in the intermediate but many more in the higher risk category than $\mathrm{CHADS}_{2}$. OAC use was only weakly associated with risk estimated by both schemes and there was significant evidence of likely under-treatment. Only $43 \%$ of all patients with AF were currently anticoagulated (although 59\% of all patients had received OAC at some point since AF diagnosis). Moreover, $3633(18 \%)$ of all patients were receiving

Table 3. Current treatment and ever anticoagulation by risk stratification for 20443 patients with atrial fibrillation without rheumatic heart disease or valve replacement, and diagnosed for at least 12 weeks.

\begin{tabular}{|c|c|c|c|c|c|c|c|}
\hline & \multirow{2}{*}{$\frac{\text { All patients }}{n(\%)}$} & \multicolumn{2}{|c|}{ 'Low risk' as defined by } & \multicolumn{2}{|c|}{$\begin{array}{c}\text { 'Intermediate risk' } \\
\text { as defined by }\end{array}$} & \multicolumn{2}{|c|}{ 'High risk' as defined by } \\
\hline & & $\mathrm{CHADS}_{2}$ & $\mathrm{CHA}_{2} \mathrm{DS}_{2} \mathrm{VASC}$ & $\mathrm{CHADS}_{2}$ & $\mathrm{CHA}_{2} \mathrm{DS}_{2}$ VASc & $\mathrm{CHADS}_{2}$ & $\mathrm{CHA}_{2} \mathrm{DS}_{2} \mathrm{VASC}$ \\
\hline & $n=20443$ & $n=3218$ & $n=1061$ & $n=6163$ & $n=1955$ & $n=11062$ & $n=17427$ \\
\hline $\begin{array}{l}\text { No current antithrombotic } \\
\text { treatment }\end{array}$ & $17.8 \%$ & $27.0 \%$ & $39.4 \%$ & $17.5 \%$ & $23.4 \%$ & $15.2 \%$ & $15.8 \%$ \\
\hline Current antiplatelet only ${ }^{a}$ & $38.9 \%$ & $34.5 \%$ & $30.0 \%$ & $39.4 \%$ & $34.3 \%$ & $39.9 \%$ & $39.9 \%$ \\
\hline Current anticoagulant only & $39.1 \%$ & $35.2 \%$ & $28.6 \%$ & $38.3 \%$ & $38.2 \%$ & $39.7 \%$ & $39.2 \%$ \\
\hline $\begin{array}{l}\text { Current anticoagulant plus } \\
\text { antiplatelet }^{c}\end{array}$ & $4.3 \%$ & $3.3 \%$ & $2.1 \%$ & $4.8 \%$ & $4.1 \%$ & $5.2 \%$ & $5.0 \%$ \\
\hline All current anticoagulant ${ }^{d}$ & $43.3 \%$ & $38.5 \%$ & $30.6 \%$ & $43.1 \%$ & $42.3 \%$ & $44.9 \%$ & $44.2 \%$ \\
\hline Anticoagulant ever since diagnosis & $58.5 \%$ & $53.0 \%$ & $48.4 \%$ & $57.4 \%$ & $57.7 \%$ & $60.8 \%$ & $59.2 \%$ \\
\hline
\end{tabular}

a31.9\% on aspirin only, $4.2 \%$ on dipyridamole or clopidogrel only, $2.8 \%$ on aspirin and (clopidogrel or dipyridamole) and $0.02 \%$ on all three antiplatelets.

${ }^{\mathrm{b}} 0.5 \%$ additionally prescribed an antiplatelet drug other than aspirin. ${ }^{\circ} 0.2 \%$ additionally prescribed an antiplatelet drug other than aspirin.

${ }^{\mathrm{d}} 0.3 \%$ prescribed an oral anticoagulant other than warfarin. 
Table 4. Patient and practice variables associated with current prescription of anticoagulation for 20443 patients with atrial fibrillation without rheumatic heart disease or valve replacement, and diagnosed for at least 12 weeks. Univariable and adjusted odds ratios are estimated in a multilevel model to account for clustering by practice. Adjustment was by variables shown in the table.

\begin{tabular}{|c|c|c|c|}
\hline Variable $^{a}$ & $\begin{array}{c}\text { No. (\%) of patients currently } \\
\text { anticoagulated }\end{array}$ & $\begin{array}{l}\text { Multilevel univariable } \\
\text { odds ratio }(95 \% \mathrm{Cl})\end{array}$ & $\begin{array}{l}\text { Multilevel adjusted } \\
\text { odds ratio }(95 \% \mathrm{Cl})^{\mathrm{b}}\end{array}$ \\
\hline \multicolumn{4}{|l|}{ Patient level variables } \\
\hline \multicolumn{4}{|l|}{ Age } \\
\hline$<45$ years $(n=273)^{c}$ & $51(18.7)$ & $0.21(0.15-0.28)$ & $0.26(0.19-0.36)$ \\
\hline $45-54$ years $(n=640)^{c}$ & 204 (31.9) & $0.43(0.36-0.51)$ & $0.50(0.41-0.60)$ \\
\hline $55-64$ years $(n=2282)^{c}$ & 1001 (43.9) & $0.70(0.63-0.77)$ & $0.70(0.63-0.78)$ \\
\hline $65-74$ years $(n=5265)^{c}$ & $2750(52.2)$ & 1 & 1 \\
\hline $75-84$ years $(n=7573)^{c}$ & $3647(48.2)$ & $0.85(0.79-0.91)$ & $0.83(0.77-0.89)$ \\
\hline $85+$ years $(n=4410)^{c}$ & $1208(27.4)$ & $0.34(0.32-0.38)$ & $0.33(0.30-0.36)$ \\
\hline \multicolumn{4}{|l|}{ Gender } \\
\hline Male $(n=11$ 170) & $5179(46.4)$ & 1 & 1 \\
\hline Female $(n=9273)$ & $3682(39.7)$ & $0.76(0.72-0.81)$ & $0.90(0.85-0.96)$ \\
\hline \multicolumn{4}{|l|}{ Co-medication } \\
\hline $\begin{array}{l}\text { No. of repeat oral drugs } \\
\text { excluding anticoagulants }\end{array}$ & $1464(37.6)$ & 1 & 1 \\
\hline \multicolumn{4}{|l|}{$0-2$ drugs $(n=3892)$} \\
\hline $3-5$ drugs $(n=7804)$ & $3826(49.0)$ & $1.53(1.41-1.66)$ & $1.33(1.21-1.45)$ \\
\hline $6-8$ drugs $(n=5899)$ & $2519(42.7)$ & $1.17(1.08-1.28)$ & $0.93(0.84-1.02)$ \\
\hline $9-11$ drugs $(n=2161)$ & $807(37.3)$ & $0.93(0.83-1.04)$ & $0.67(0.59-0.76)$ \\
\hline $12+$ drugs $(n=687)$ & $245(35.7)$ & $0.86(0.72-1.02)$ & $0.55(0.45-0.66)$ \\
\hline \multicolumn{4}{|l|}{ AF type } \\
\hline Chronic AF ( $n=17886)$ & $8349(46.7)$ & 1 & 1 \\
\hline Paroxysmal AF $(n=2557)$ & $512(20.0)$ & $0.27(0.24-0.30)$ & $0.26(0.23-0.29)$ \\
\hline \multicolumn{4}{|l|}{ Comorbidity } \\
\hline No diabetes $(n=17050)$ & 7263 (42.6) & 1 & 1 \\
\hline Diabetes $(n=3393)$ & $1598(47.1)$ & $1.19(1.11-1.28)$ & $1.18(1.08-1.28)$ \\
\hline No heart failure $(n=16$ 194) & 6788 (41.9) & 1 & 1 \\
\hline Heart failure $(n=4249)$ & $2073(48.8)$ & $1.36(1.27-1.45)$ & $1.45(1.35-1.57)$ \\
\hline No hypertension $(n=9240)$ & $3763(40.7)$ & 1 & 1 \\
\hline Hypertension ( $n=11203)$ & $5098(45.5)$ & $1.23(1.16-1.30)$ & $1.19(1.11-1.27)$ \\
\hline No stroke/TIA ( $n=17863)$ & 7509 (42.5) & 1 & 1 \\
\hline Stroke/TIA $(n=2760)$ & $1352(49.0)$ & $1.33(1.24-1.42)$ & $1.48(1.35-1.62)$ \\
\hline No PVD $(n=19$ 069) & 8295 (43.5) & 1 & 1 \\
\hline $\operatorname{PVD}(n=1374)$ & $566(41.2)$ & $0.94(0.84-1.05)$ & $0.88(0.78-0.99)$ \\
\hline \multicolumn{4}{|l|}{ Relative contra-indications } \\
\hline No dementia $(n=19437)^{\mathrm{d}}$ & $8717(44.8)$ & 1 & 1 \\
\hline Dementia $(n=1006)^{d}$ & $144(14.3)$ & $0.21(0.17-0.25)$ & $0.25(0.20-0.30)$ \\
\hline No history PU ( $n=18$ 384) & 8065 (43.9) & 1 & 1 \\
\hline History PU $(n=2059)$ & $796(38.7)$ & $0.82(0.75-0.91)$ & $0.79(0.72-0.88)$ \\
\hline \multicolumn{4}{|l|}{ Practice level variables } \\
\hline \multicolumn{4}{|l|}{ Training status } \\
\hline Not training $(n=10929)^{a}$ & $4913(45.0)$ & 1 & 1 \\
\hline Training $(n=9218)$ & 3801 (41.2) & $0.86(0.77-0.96)$ & $0.87(0.78-0.97)$ \\
\hline \multicolumn{4}{|l|}{ Rurality } \\
\hline Primary city $(n=6955)$ & $2830(40.7)$ & 1 & 1 \\
\hline Urban area $(n=6980)$ & 2992 (42.9) & $1.09(0.96-1.24)$ & $1.07(0.94-1.23)$ \\
\hline Accessible $(n=3322)$ & $1534(46.2)$ & $1.29(1.11-1.48)$ & $1.20(1.03-1.40)$ \\
\hline Remote $(n=1479)$ & $677(45.8)$ & $1.21(1.11-1.48)$ & $1.13(0.89-1.43)$ \\
\hline Very remote $(n=1707)$ & $828(48.5)$ & $1.40(1.17-1.69)$ & $1.44(1.19-1.74)$ \\
\hline \multicolumn{4}{|l|}{ High risk prescribing rate } \\
\hline Quartile 1 low $(n=6187)$ & $2508(40.5)$ & 1 & 1 \\
\hline Quartile $2(n=5301)$ & 2276 (42.9) & $1.05(0.92-1.20)$ & $1.01(0.87-1.17)$ \\
\hline Quartile $3(n=4896)$ & $2160(44.1)$ & $1.10(0.96-1.27)$ & $1.05(0.90-1.23)$ \\
\hline Quartile 4 high $(n=4059)$ & $1917(47.2)$ & $1.29(1.12-1.49)$ & $1.25(1.07-1.45)$ \\
\hline
\end{tabular}

${ }^{a}$ Adjusted for the confounders shown in the table. Other variables examined but not significantly associated in adjusted model were socioeconomic deprivation (based on the postcode sector of the patient's address (25)), duration of atrial fibrillation, presence of coronary heart disease, practice list size, whether the practice held a standard General Medical Services or a locally varied Personal Medical Services contract, whether the practice dispensed its own prescriptions. AF: atrial fibrillation; TIA: transient ischemic attack; PVD: peripheral vascular disease; PU: peptic ulcer.

bPractice level data missing for 6 practices and 296 patients.

cAge in years assessed on 31 March 2007.

${ }^{d}$ Dementia (defined as either a relevant Read code or prescription of an acetylcholinesterase inhibiting drug that is exclusively used in dementia (26). 


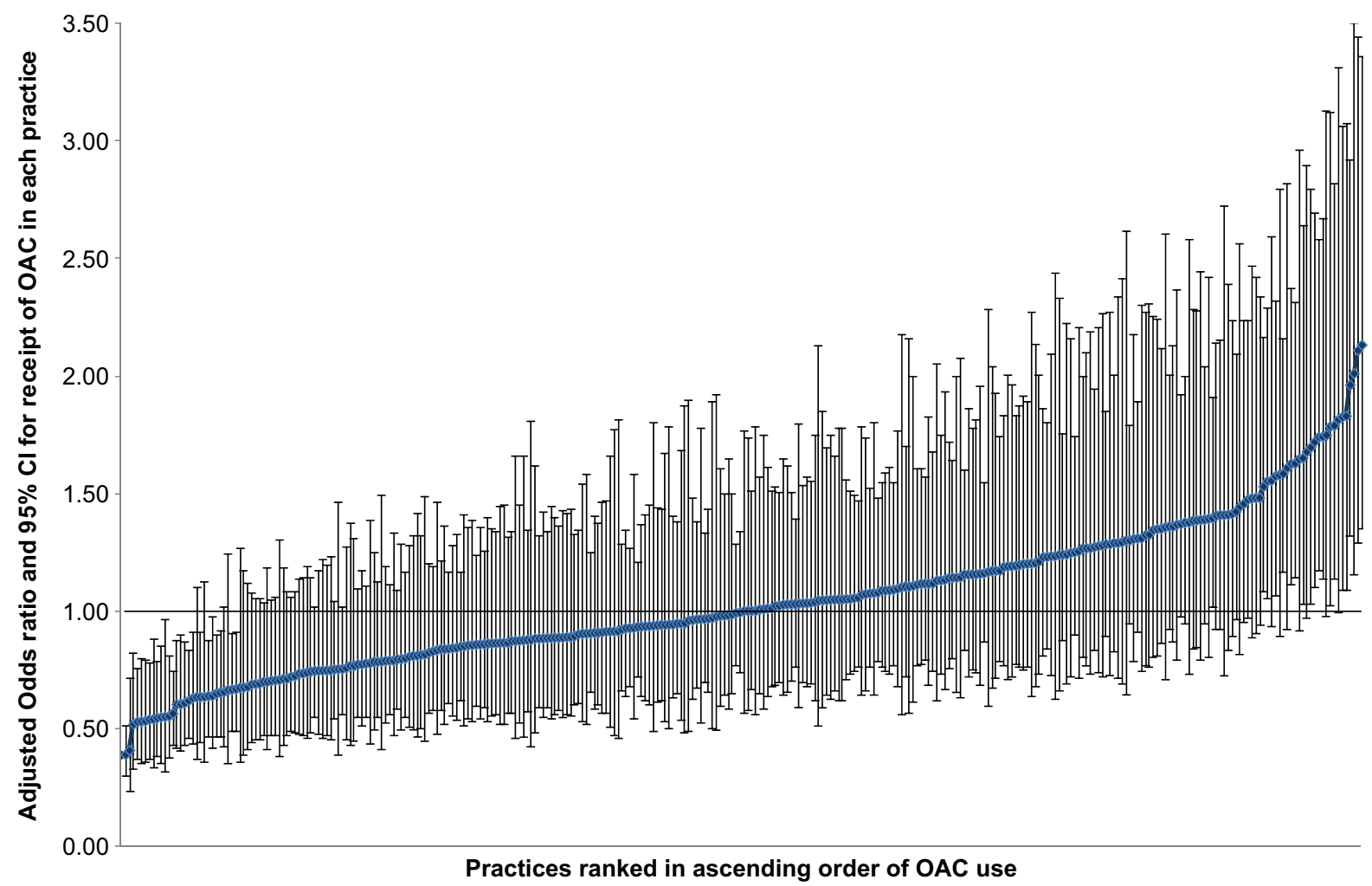

Figure 1. Variation between practices in receipt of OAC by individual patients (odds ratio and $95 \%$ confidence intervals) after adjustment for patient characteristics. An odds ratio of 1.00 represents the average across all 315 practices.

neither antiplatelets nor OAC, including many at high-risk of stroke. The study also found some evidence of potential overtreatment in terms of OAC use in patients classified at low-risk of stroke, although this was less common than under-treatment. In addition, $873(5 \%)$ of all patients were co-prescribed OAC and antiplatelets (for which there is only a narrow indication in AF patients within the first year after acute coronary syndrome (30-32)). Use of OAC was only weakly associated with known risk factors for stroke in $\mathrm{AF}$ (such as previous stroke or TIA, heart failure, and hypertension) and was much less commonly prescribed to older patients (where the net-benefit of OAC use is highest (4)). OAC use was also much lower in patients with paroxysmal AF, in those on many other drugs and those with relative contraindications.

After adjustment for patient characteristics, OAC uptake varied more than five-fold between practices, with patients in more remote practices, non-training practices and those with high levels of high-risk prescribing being more likely to be prescribed OAC.

\section{Strengths and limitations of the study}

As with all observational studies using routine clinical data, the findings are potentially subject to residual confounding due to unmeasured confounders, and inconsistencies in the recording of data. However, a strength is that the study used data for a population of patients that is representative of Scotland in terms of age and socioeconomic deprivation (23), and some factors support the accuracy of the dataset used in this study. In the UK National Health Service, patients register with one general practice, which functions as the gatekeeper and (although specialists may advise initiation of chronic drug treatment) GPs are responsible for prescribing OAC and antiplatelets. In addition, all examined morbidities and prescribing are included in QOF, which incentivises accurate documentation. Nevertheless, several factors that have been shown to influence prescribers' decision making (33) could not be accounted for here due to inconsistent documentation, including alcohol consumption, increased falls risk, patients' ability to comply with OAC treatment and patient preference.

\section{Comparison with existing literature}

The finding that in this Scottish population, $\mathrm{CHADS}_{2}$ classified a relatively large number of patients with AF $(30.3 \%)$ in the intermediate-risk category is a deliberate consequence of $\mathrm{CHAD}_{2} \mathrm{VA}_{2} \mathrm{Sc}$ placing a focus on identifying a small number of patients who do not need to be anticoagulated (22) and consistent with the findings of a recent population-based study conducted in the UK (13). Our findings also confirm recent studies reporting suboptimal $(\sim 50 \%)$ uptake of OAC in high-risk patients 
$(12,13)$, a lower tendency to use OAC in patients with relative contraindications (13) and in those with paroxysmal AF $(34,35)$.

The finding that $59 \%$ of all patients had received OAC at some point since AF diagnosis but only $43 \%$ were current $\mathrm{OAC}$ users is also consistent with previous estimates that over a quarter of patients with AF commencing OAC do not take it long term (35). A new finding of our study is the substantial variation between practices in their tendency to prescribe OAC. While the reasons for this variation require further investigation, a possible explanation is that remoteness, non-training status and higher levels of high-risk prescribing are in fact proxies for a lesser awareness or higher tolerance of medication safety risks.

\section{Implications for clinical practice and future research}

In this study, OAC use was only weakly associated with risk estimated by both schemes suggesting that risk stratification is not routinely used in decision making and many patients at high risk of stroke were found to have never been treated with OAC. In addition, there appears to be a misconception by prescribers that stroke risk is lower in paroxysmal than in chronic AF (OAC use in patients with paroxysmal AF was much lower) (4), and there was considerable variation in OAC use between practices. All of these findings make it very likely that OAC use in primary care could be increased.

In the UK, general practitioners are now financially rewarded both for documenting $\mathrm{CHADS}_{2}$ assessment and for using OAC in up to $70 \%$ of AF patients with $\mathrm{CHADS}_{2} \geq 2$ (17) and support software has been developed and implemented in practices' electronic medical records (EMRs), which can flag up patients with a $\mathrm{CHADS}_{2}$ score of two not receiving warfarin (36). While these strategies may help to increase the use of stroke risk stratification tools in clinical practice, it remains to be seen whether they will increase OAC prescribing in patients with AF. This is partly because almost one third of patients with AF were classified by $\mathrm{CHADS}_{2}$ as intermediate-risk, where aspirin may be perceived as a legitimate and less burdensome alternative to OAC. Using $\mathrm{CHA}_{2} \mathrm{DS}_{2} \mathrm{VASc}$ in line with current ESC guidance has the advantage of prompting prescribers to consider OAC as the preferred choice in virtually all AF patients (94.8\% of patients in this study had a $\mathrm{CHA}_{2} \mathrm{DS}_{2} \mathrm{VASc} \geq 1$ ), but lower rates of OAC use in the elderly, in patients on many other drugs or with relative contraindications suggest that prescribers may place greater weight on concerns about adverse events than estimated stroke risk, which is not always irrational. Many patients who are classified as high-risk by $\mathrm{CHA}_{2} \mathrm{DS}_{2}$ VASc have individual stroke risk below that where OAC is clearly beneficial (20), although in most AF patients, the estimated benefit of OAC outweighs any excess risk of bleeding $(4,32)$. In addition, given that clinical trials (even those with broad eligibility criteria) underestimate bleeding risk from OAC use in clinical practice (37) and that many patients prefer not to take OAC, bleeding risk and patient preference are likely to remain important drivers for decision making in AF (32). Newer OAC, which do not require regular INR monitoring, may make OAC use more acceptable to patients and might be safer, but limited trial evidence in patients at intermediate risk of stroke and high treatment costs are likely to limit their use in many countries in the foreseeable future $(38,39)$. To enable clinicians and patients to better balance stroke and bleeding risk, a number of bleeding risk assessment tools have been developed $(40,41)$, but their utility in practice is limited by the clinical dilemma that many risk factors for stroke and major haemorrhage overlap (42).

In summary, therefore, promoting the uptake of current stroke risk stratification schemes (alone or in combination with current bleeding risk assessment instruments) is a plausible but untested strategy to improve decision making in AF.

\section{Conclusion}

Treatment with OAC and aspirin was largely unrelated to stroke risk estimated by both risk-stratification schemes examined, with considerable evidence of undertreatment, and some evidence of over-treatment. The poor alignment of prescribing practices with current stroke risk assessment tools may in part be explained by the limited use of these tools in clinical practice or by (perceived or actual) barriers to managing treatment with OAC, but may also be due to inherent limitations of existing instruments. Although potential benefits of using risk-stratification schemes seem plausible, the impact of such schemes on uptake of OAC or patientcentred outcomes can, therefore, not be assumed and should be evaluated in pragmatic trials.

\section{ACKNOWLEDGEMENTS}

The authors would like to thank the practices who contributed data to the SPICE-PC programme and allowed the anonymised data to be used for research; the Primary Care Clinical Information Unit at University of Aberdeen who carried out the initial data extraction and management, particularly Katie Wilde and Fiona Chaloner; and project advisory group members Colin Simpson, Colin McCowan, Lorna Scahill and Mairi Scott.

\section{FUNDING}

This work was supported by NHS quality improvement Scotland (better measures project grant supporting KB) and Scottish government health directorates chief 
scientist office applied research programme grant 07/02 supporting TD. Study design, data analysis, interpretation and publication were the responsibility of the research team who had sole access to the data.

\section{ETHICS}

Analysis used fully anonymised data compliant with the PCCIU research governance process, and NHS research ethics service review was, therefore, not required.

Declaration of interest: The authors report no conflicts of interest. The authors alone are responsible for the content and writing of the paper.

\section{REFERENCES}

1. Stewart S HC, Hole DJ, McMurray JJ. Population prevalence, incidence, and predictors of atrial fibrillation in the Renfrew/Paisley study. Heart 2001;86:516-21.

2. Miyasaka YM, Barnes BJ, Gersh, Cha SS, Bailey KR, Abhayaratna WP, et al. Secular trends in incidence of atrial fibrillation in Olmsted County, Minnesota, 1980 to 2000, and implications on the projections for future prevalence. Circulation 2006;114:119-25.

3. Go AS HE, Phillips KA, Chang Y, Henault LE, Selby JV, Singer DE. Prevalence of diagnosed atrial fibrillation in adults: National implications for rhythm management and stroke prevention: The anticoagulation and risk factors in atrial fibrillation (ATRIA) Study. J Am Med Assoc. 2001;285:2370-5.

4. Camm AJ, Kirchhof P, Lip GYH, Schotten U, Savelieva I, Ernst S, et al. Guidelines for the management of atrial fibrillation. Europace 2010;12:1360-420.

5. van Walraven C, Hart RG, Connolly S, Austin PC, Mant J, Hobbs FDR, et al. Effect of age on stroke prevention therapy in patients with atrial fibrillation. Stroke 2009;40:1410-6.

6. Hart RG, Pearce LA, Aguilar MI. Meta-analysis: Antithrombotic therapy to prevent stroke in patients who have nonvalvular atrial fibrillation. Ann Intern Med. 2007;146:857-67.

7. Thomson R, Parkin D, Eccles $M$, Sudlow $M$, Robinson $A$. Decision analysis and guidelines for anticoagulant therapy to prevent stroke in patients with atrial fibrillation. Lancet 2000; 355:956-62.

8. Jowett S, Bryan S, Mant J, Fletcher K, Roalfe A, Fitzmaurice D, et al. Cost effectiveness of warfarin versus aspirin in patients older than 75 years with atrial fibrillation. Stroke 2011;42: 1717-21.

9. Ogilvie IM, Welner SA, Cowell W, Lip GY. Ischaemic stroke and bleeding rates in 'real-world' atrial fibrillation patients. J Thromb Haemost. 2011;106:34-44.

10. National Institute for Health and Clinical Excellence. Atrial fibrillation: National clinical guideline for management in primary and secondary care. London: NICE; 2006.

11. Singer DE, Albers GW, Dalen JE, Fang MC, Go AS, Halperin JL, et al Antithrombotic therapy in atrial fibrillation: American College of Chest Physicians evidence-based clinical practice guidelines. Chest 2008;133 (6 Suppl):546-92.

12. Ogilvie IM, Newton $N$, Welner $\mathrm{S}$. Underuse of oral anticoagulants in atrial fibrillation: A systematic review. Am J Med. 2010:638-45.

13. Holt TA, Hunter TD, Gunnarsson C, Khan N, Cload P, Lip GYH Risk of stroke and oral anticoagulant use in atrial fibrillation: a cross-sectional survey. Brit J Gen Pract. 2012;62:710-17.
14. Gage BF, Waterman AD, Shannon W, Boechler M, Rich MW, Radford MJ. Validation of clinical classification schemes for predicting stroke: Results from the national registry of atrial fibrillation. J Am Med Assoc. 2001;285:2864-70.

15. Fuster V, Ryden LE, Cannom DS, Crijns HJ, Curtis $A B$, Ellenbogen KA, et al. American College of Cardiology Foundation/ American Heart Association Task Force on guidelines for the management of patients with atrial fibrillation: A report of the 2011 ACCF/AHA/HRS focused updates incorporated into the ACC/AHA/ ESC 2006 practice guidelines. Circulation 2011;123:e269-e367.

16. Borman NL, Kalra PA, Kalra PR. Acute kidney injury in patients with decompensated heart failure. Brit J Hosp Med. 2010;71: 269-75.

17. British Medical Association and NHS Employers. Quality and outcomes framework for 2012/13. Guidance for PCOs and practices (p118). Available at http://www.nhsemployers.org/ Aboutus/Publications/Documents/QOF_2012-13.pdf (accessed 12 November 2013).

18. Gorin L, Fauchier L, Nonin E, de Labriolle A, Haguenoer K, Cosnay $\mathrm{P}$, et al. Antithrombotic treatment and the risk of death and stroke in patients with atrial fibrillation and a CHADS2 score $=1$. J Thromb Haemost. 2010;103:833-40.

19. Lip GYH. Anticoagulation therapy and the risk of stroke in patients with atrial fibrillation at 'moderate risk' [CHADS2 score =1]: Simplifying stroke risk assessment and thromboprophylaxis in real-life clinical practice. J Thromb Haemost. 2010;103:683-5.

20. Karthikeyan G, Eikelboom JW. The CHADS2 score for stroke risk stratification in atrial fibrillation-friend or foe? J Thromb Haemost. 2010;104:45-8.

21. Singer DE, Albers GW, Dalen JE, Fang MC, Go AS, Halperin JL, et al. Antithrombotic therapy in atrial fibrillation. Chest 2008;133:546S92S.

22. Van Staa TP, Setakis E, Di Tanna GL, Lane DA, Lip GYH. A comparison of risk stratification schemes for stroke in 79884 atrial fibrillation patients in general practice. J Thromb Haemost. 2011;9:39-48.

23. Elder R, Kirkpatrick M, Ramsay W, MacLeod M, Guthrie B, Sutton $M$, et al. Measuring quality in primary medical services using data from SPICE. Edinburgh: Information and Statistics Division, NHS National Services Scotland; 2007.

24. NHS England: Primary Care Commissioning. QOF implementation: Business rules. Available at http://www.pcc.nhs.uk/145 (accessed 12 November 2013).

25. Carstairs V, Morris R. Deprivation and health in Scotland. Aberdeen: Aberdeen University Press; 1991.

26. Guthrie B, Clark SA, McCowan C. The burden of psychotropic drug prescribing in people with dementia: A population database study. Age Ageing 2010;39:637-42.

27. Guthrie B, McCowan C, Davey P, Simpson CR, Dreischulte T, Barnett $\mathrm{K}$. High risk prescribing in primary care patients particularly vulnerable to adverse drug events: Cross sectional population database analysis in Scottish general practice. $\mathrm{Br}$ Med J. 2011;342:d3514.

28. Dreischulte T, Grant A, McCowan C, McAnaw J, Guthrie B. Quality and safety of medication use in primary care: Consensus validation of a new set of explicit medication assessment criteria and prioritisation of topics for improvement. Br Med C Clin Pharmacol. 2012;12:5.

29. Larsen K, Merlo J. Appropriate assessment of neighbourhood effects on individual health: Integrating random and fixed effects in multilevel logistic regression. Am J Epidemiol. 2007; 161:81-8.

30. Lip G, Huber K, Andreotti F, Arnesen H, Airaksinen J, Cuisset T, et al. Antithrombotic management of atrial fibrillation patients presenting with acute coronary syndrome and/or undergoing coronary stenting: Executive summary-a consensus document of the European Society of Cardiology working group on 
thrombosis, endorsed by the European Heart Rhythm Association (EHRA) and the European Association of Percutaneous Cardiovascular Interventions (EAPCI). Eur Heart J. 2010;31: 1311-8.

31. Hansen ML, Sorensen R, Mette T, Fog-Petersen M, Rauns $\varnothing$ J, Gadsbøll N, et al. Less is more. Risk of bleeding with single, dual, or triple therapy with warfarin, aspirin, and clopidogrel in patients with atrial fibrillation. Arch Intern Med. 2010;16: 170-5.

32. Lip GYH, Andreotti F, Fauchier L, Huber K, Hylek E, Knight E, et al. Bleeding risk assessment and management in atrial fibrillation patients: A position document from the European Heart Rhythm Association, endorsed by the European Society of Cardiology Working Group on Thrombosis. Europace 2011;13:723-46.

33. Pugh D, Pugh J, Mead GE. Attitudes of physicians regarding anticoagulation for atrial fibrillation: A systematic review. Age Ageing 2011;40:675-83.

34. Nieuwlaat R, Capucci A, Lip GY, Olsson SB, Prins MH, Nieman FH, et al. Antithrombotic treatment in real-life atrial fibrillation patients: A report from the Euro Heart Survey on atrial fibrillation. Eur Heart J. 2006;27:3018-26.

35. Gallagher AM RS, Plumb J, van Staa TP. Initiation and persistence of warfarin or aspirin in patients with chronic atrial fibrillation in general practice: Do the appropriate patients receive stroke prophylaxis? J Thromb Haemost. 2008;6:1500-6.

36. NHS improvement. Guidance on risk assessment and stroke prevention for atrial fibrillation (GRASP-AF). Available at http://www. improvement.nhs.uk/graspaf/ (accessed 27 February 2013).
37. Mant J, Hobbs FR, Fletcher K, Roalfe A, Fitzmaurice D, Lip GYH, et al. Warfarin versus aspirin for stroke prevention in an elderly community population with atrial fibrillation (the Birmingham atrial fibrillation treatment of the aged study, BAFTA): a randomised controlled trial. Lancet 2007;370:493-503.

38. National Institute for Health and Clinical Excellence. Rivaroxaban for the prevention of stroke and systemic embolism in people with atrial fibrillation. NICE Technology appraisal guidance 256 . Available at http://www.nice.org.uk/nicemedia/live/13746/ 59295/59295.pdf (accessed 12 November 2013).

39. Scottish Medicines Consortium (SMC) No. (852/13). Rivaroxaban 15 and $20 \mathrm{mg}$ film-coated tablets. Available at http://www.scottishmedicines.org.uk/files/advice/rivaroxaban_Xarelto_for_AF_ FINAL_Jan_2012_for_website.pdf (accessed 12 November 2013).

40. Pisters R, Lane DA, Nieuwlaat R, de Vos CB, Crijns HJ, Lip GY. A novel user-friendly score (HAS-BLED) to assess 1-year risk of major bleeding in patients with atrial fibrillation: The Euro Heart Survey. Chest 2010;138:1093-100.

41. Gage $B F$, Yan $Y$, Milligan $P E$, Waterman AD, Culverhouse $R$, Rich MW, et al. Clinical classification schemes for predicting hemorrhage-results from the National Registry of Atrial Fibrillation (NRAF). Am Heart J. 2006;151:713-9.

42. Hohnloser SH. Stroke prevention versus bleeding risk in atrial fibrillation-a clinical dilemma. J Am Coll Cardiol. 2011;57: 181-3.

43. Pamukcu B, Lip GYH, Lane DA. Simplifying stroke risk stratification in atrial fibrillation patients: Implications of the CHA2DS2-VASC risk stratification scores. Age Ageing 2010:afq059. 